\title{
Organic Light-emitting Devices with Different Hole-injection Layer
}

\author{
${ }^{a}$ Hui-shan Yang, Xiao-ling Chen and ${ }^{*}$ Li-shuang Wu
}

\author{
College of Physics and Information Engineering, Quanzhou Normal University, Quanzhou 362000, \\ People's Republic of China \\ a email: yanghuishan1697@163.com;
}

*Author to whom correspondence should be addressed:b email: lishuangw@126.com;

\begin{abstract}
Keywords: Organic Light-emitting Devices; Hole Injection Layer; Luminance; Efficiency; The Commission Internationale de 1'Eclairage (CIE) Coordinates
\end{abstract}

\begin{abstract}
Organic light-emitting device have been realized by using 4,4',4'-tris $\{N$,(3-methylphenyl)- $N$-phenylamin triphenylamine ( m-MTDATA) , $N, \quad N$ '-bis- (1-naphthyl) $-N$, $N$ '-diphenyl-1, 1'-biph-enyl-4, 4'-diamine(NPB), 4, 4 (-N,N)- dicarbazole-biphenyl (CBP), and NPB:CBP as holes injection layer, respectively, and [2-methyl-6- [2-(2, 3,6,7-tetrahydro-1H, red fluorescent dye 4- (dicyanomethylene)-2-t- butyle-6- (1,1, 7, 7-tetramethyljulolidyl-9-enyl) 4H- pyran (DCJTB), together with well known green fluorescent dye quinacridone (QAD) as emitting layer, tris(8-hydroxyquinoline) aluminium $\left(\mathrm{Alq}_{3}\right)$ act as electron transport layer. WOLEDs was obtained with CBP or NPB:CBP as holes injection layer, the Commission Internationale de 1'Eclairage (CIE) coordinates of the device $\mathrm{C}$ and $\mathrm{D}$ change from $(0.408,0.4202)$ at $4 \mathrm{~V}$ to $(0.4465,0.4646)$ at $11 \mathrm{~V}$, $(0.248,0.2791)$ at $4 \mathrm{~V}$ to $(0.4616,0.4366)$ at $16 \mathrm{~V}$, respectively. Its maximum luminance and maximum current efficiency of the device A was $3126 \mathrm{~cd} / \mathrm{m}^{2}$ at $11 \mathrm{~V}$, and $2.28 \mathrm{~cd} / \mathrm{A}$ at $13 \mathrm{~V}$, respectively.
\end{abstract}

\section{Introduction}

Organic light-emitting devices (OLEDs ) are commercially used in display productions, such as mobile phones, laptops, TVs. And they are regarded as a powerful solid-state lighting candidate because of their potential applications in full-color flat-panel displays, mobile displays, and lighting devices due to their excellent advantages of ultra-thin thickness, high-contrast ratio, wide-viewing angle, fast response, high-flexibility, and low power-consumption [1]. As a double carrier injection device, the efficiency of OLED typically depends on carrier injection and balance, determined by the carrier injection barrier at organic/electrode interfaces and density in emissive layer, respectively. Many researchers have been made to improve carrier injection and balance [2-10]. As a consequence, the improved device properties are achieved. Besides the injection and balance of carriers, recombination zone of excitons, i.e. bound states formed by the combination of holes and electrons, is also critical to the properties (e.g. efficiency, color) of OLEDs. Therefore, in order to precisely control recombination zone of OLEDs and obtain better device properties, it is greatly significant to investigate recombination zone of OLEDs. Generally, it is difficult to experimentally probe the spatial distribution and location of the exciton recombination zone. However, the alteration of recombination zone can be in directly reflected by the electroluminescent (EL) spectra of OLEDs. Some attempts have been under taken to investigate the variation of exciton recombination zone using EL spectra [11-18].

Holes injection layer (HIL) and hole transport layer (HTL) are largely influence of devices. Here we study the difference hole injection layer at the interface of OLEDs between anode and emitting layer. Specifically, we employed 4,4',4"-tris $\{N,-\quad$ (3-methylphenyl)- $N$-phenylamin $\}$ triphenylamine ( m-MTDATA), $N, N^{\prime}$-bis -(1-naphthyl)- $N$, N'-diphenyl-1, 1'-biph-enyl-4, 4'-diamine(NPB), 4, 
4(-N,N)- dicarbazole-biphenyl (CBP), and NPB:CBP as holes injection layer, respectively.

\section{Experimental Details}

Figure 1 shows the structure of device. The structure of the device is ITO/ m-MTDTA $(35 \mathrm{~nm}) / \mathrm{NPB}(15 \mathrm{~nm}) / \mathrm{DCJTB}(0.5 \mathrm{~nm}) / \mathrm{Alq}(5 \mathrm{~nm}) \quad / \mathrm{QAD}(0.5 \mathrm{~nm}) \quad / \quad \mathrm{Alq}(55 \mathrm{~nm}) / \quad \mathrm{LiF}(1 \mathrm{~nm}) / \mathrm{Al}$, $\mathrm{ITO} / \mathrm{NPB}(50 \mathrm{~nm}) / \mathrm{DCJTB}(0.5 \mathrm{~nm}) / \mathrm{Alq}(5 \mathrm{~nm}) / \quad \mathrm{QAD}(0.5 \mathrm{~nm}) / \mathrm{Alq}(55 \mathrm{~nm}) / \quad \mathrm{LiF}(1 \mathrm{~nm}) / \mathrm{Al}, \quad \mathrm{ITO} \quad /$ $\mathrm{CBP}(35 \mathrm{~nm}) / \mathrm{NPB}(15 \mathrm{~nm}) / \mathrm{DCJTB}(0.5 \mathrm{~nm}) / \mathrm{Alq}(5 \mathrm{~nm}) / \mathrm{QAD}(0.5 \mathrm{~nm}) / \mathrm{Alq}(55 \mathrm{~nm}) / \mathrm{LiF}(1 \mathrm{~nm}) / \mathrm{Al}, \mathrm{ITO} /$ NPB:CBP $(35 \mathrm{~nm}) / \mathrm{NPB}(15 \mathrm{~nm}) / \operatorname{DCJTB}(0.5 \mathrm{~nm}) / \mathrm{Alq}(5 \mathrm{~nm}) / \mathrm{QAD}(0.5 \mathrm{~nm}) / \operatorname{Alq}(55 \mathrm{~nm}) / \mathrm{LiF}(1 \mathrm{~nm}) / \mathrm{Al}$ $(2: 1)$, and the corresponding devices are named $\mathrm{A}, \mathrm{B}, \mathrm{C}$ and $\mathrm{D}$, respectively.

\begin{tabular}{|c|}
\hline LiF(1 nm)/Al(200 nm) \\
\hline $\operatorname{Alq}_{3}(55 \mathrm{~nm})$ \\
\hline QAD(0.5 nm) \\
\hline $\operatorname{Alq}(5 \mathrm{~nm})$ \\
\hline DCJTB $(0.5 \mathrm{~nm})$ \\
\hline NPB(15 nm) \\
\hline Hole iniection laver(35 $\mathrm{nm})$ \\
\hline ITO \\
\hline
\end{tabular}

Figure 1 The device structure of the OLEDs

Organic layers were deposited by high-vacuum ( $10^{-6}$ Torr) thermal evaporation onto a cleaned indium tin oxide (ITO) coated glass substrate. The layer thickness of the deposited material was monitored using an oscillating quartz thickness monitor. EL spectra and CIE coordination of the devices were measured by PR655 spectra scan spectrometer and the current-voltage- brightness characteristics were simultaneously measured by a Keithley 2400 programmable voltage-current source. All measurements were carried out at room temperature under ambient conditions.

\section{Results and Discussion}

In general, the EL spectra and the CIE coordinates of the organic light-emitting device are strongly influenced by the different holes injection layer and applied voltage. Figure 2(a) shows the EL spectra of devices A-D at different applied voltage. The normalized EL spectra of the devices A,B and D shows three main emission peaks at $520 \mathrm{~nm}$ and $656 \mathrm{~nm}$ originating from QAD and DCJTB, the normalized EL spectra of the devices $C$ shows three main emission peaks at $520 \mathrm{~nm}, 650 \mathrm{~nm}$ originating from QAD and DCJTB, 550nm originating from Alq, respectively. The concept of multiplayer structure allows control on the spectral characteristics by adjusting the exciton-recombination zone spatially. In our devices, DCJTB trapping excitons and originating red emitting, with the applied voltage increased, the green emission is enhanced compared with that red emission, this may be attributed to the more excitons formed at the Alq/QAD interface, and green emission is enhanced may be attributed to the complete Förster energy transfer from Alq3 to QAD.

Figure 2(b) shows the CIE coordinates of devices A-D at different voltage. From the figure we can see that device $\mathrm{C}$ has closed white emitting among the four devices. The CIE coordinates of device $\mathrm{C}$ change from $(0.4324,0.4482)$ at $4 \mathrm{~V}$ to $(0.4465,0.4646)$ at $10 \mathrm{~V}$, The CIE coordinates of device A change from $(0.6291,0.341)$ at $4 \mathrm{~V}$ to $(0.4916,0.4224)$ at $16 \mathrm{~V}$, The CIE coordinates of device $\mathrm{B}$ change 
from $(0.6341,0.3418)$ at $4 \mathrm{~V}$ to $(0.5198,0.4128)$ at $16 \mathrm{~V}$, The CIE coordinates of device $\mathrm{D}$ change from $(0.2837,0.2982)$ at $4 \mathrm{~V}$ to $(0.4616,0.4366)$ at $15 \mathrm{~V}$, respectively. The main changes in color with the different holes injection layer, m-MTDTA, NPB, CBP or CBP:NPB has different hole mobility and energy barrier injected from the ITO side, while the number of hole combined with electron has dissimilar resulting in the whole emitting layer within the diffuse length of excitons. In contrast, the CIE coordinates of device $\mathrm{C}$ independent significantly of applied voltage. This is due to CBP has the barrier of holes at the ITO/CBP interface is $1.6 \mathrm{eV}$ (but ITO/NPB interface is $0.8 \mathrm{eV}$ ), which blocks off much hole injected to the organic layer, the results showed that the devices yielded comparatively stable of electroluminescence spectra and CIE color coordinates results stable white emission.
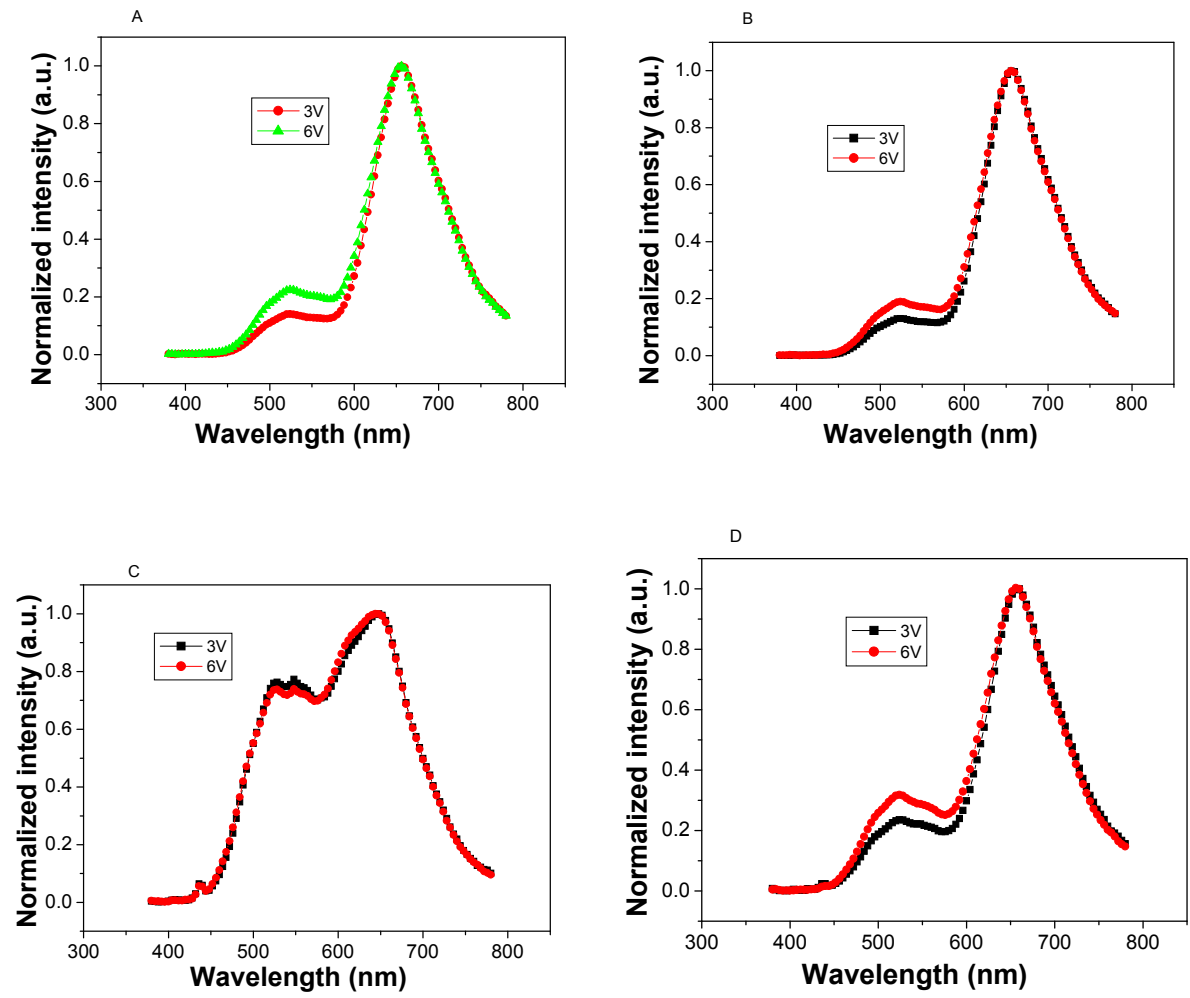

Figure 2(a). Normalized EL intensity of the device A-D at different voltage

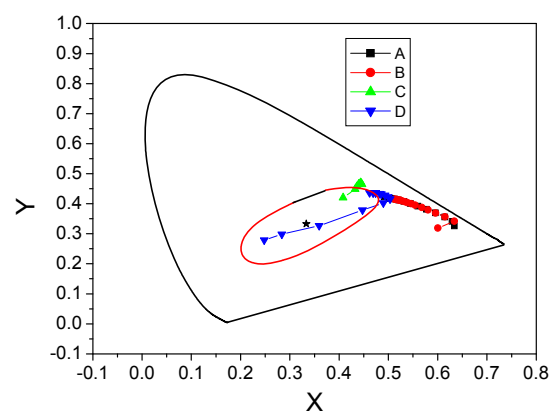

Figure 2 (b) CIE coordinates of devices A-D at different voltage

The applied voltage $(V)$ dependence of current density $(I)$ and luminance are shown in Figure 3. 
The charge transport can be facilitated with the use of m-MTDTA as an HIL. The m-MTDTA is strong material of lowest unoccupied molecular orbital (LUMO) level located around 5.1Ev (relative to the vacuum level), which leads to a different hole-injecting mechanism from other HILs. Generally charge transport enhancement is achieved by adjusting energy levels of layers in contact. But in the case of $\mathrm{CBP} / \mathrm{HTL}$ interface, the main action is blocking holes that take place at the interface. From Fig.3, it is seen that the luminance of device $\mathrm{A}$ is higher than that of another devices. For both four devices the best L-V characteristics were obtained with m-MTDTA and NPB. These data shows that the luminance of device A has $3126 \mathrm{~cd} / \mathrm{m} 2$ ) at $11 \mathrm{~V}$.

Figure 4 shows the EL efficiency of device A-D. The maximum current efficiencies of device A-D are $2.68 \mathrm{~cd} / \mathrm{A}$ at $13 \mathrm{~V}, 1.72 \mathrm{~cd} / \mathrm{A}$ at $15 \mathrm{~V}, 0.29 \mathrm{~cd} / \mathrm{A}$ at $6 \mathrm{~V}, 0.63 \mathrm{~cd} / \mathrm{A}$ at $4 \mathrm{~V}$, respectively. The device $\mathrm{A}$ has best efficiency due to holes and electrons more balanced in emitting layer. The key EL characteristics of Devices A-D are shown Table 1.
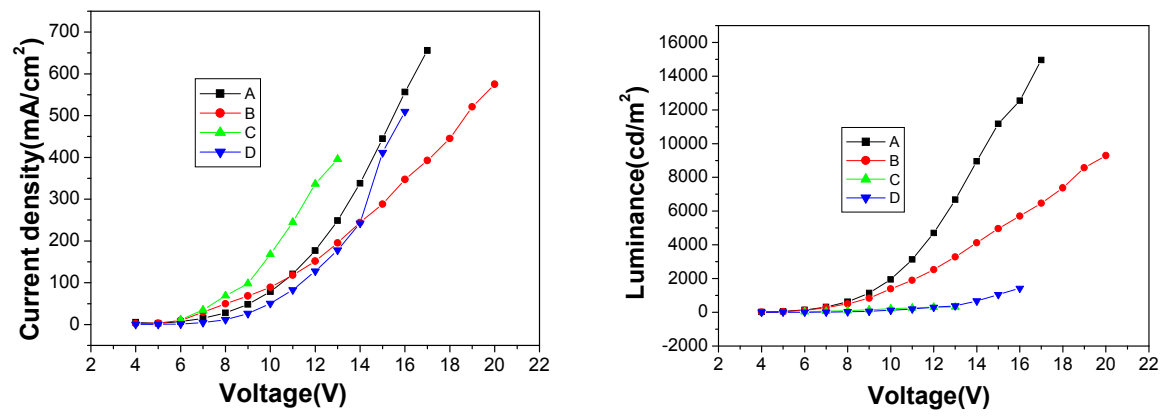

Figure 3 The current density-voltage and the luminance-voltage characteristics of devices

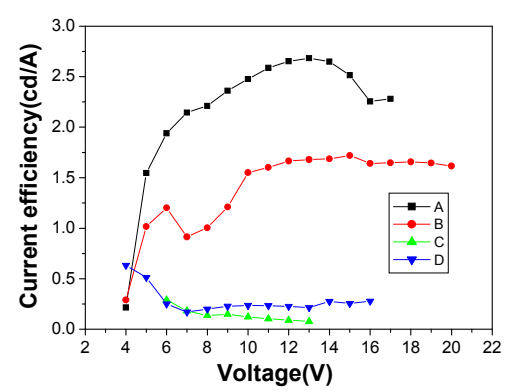

Figure 4 The current efficiency- voltage characteristics of devices

From the characteristics of devices, we can see that device A has best performance such as current efficiency and luminance, device $\mathrm{C}$ has best performance such as CIE coordinates, which is attributed to a balance of excitons distribute in emitting layers. As the thickness of DCM2 and QAD is increase, the emission from green and red along with a substantial increase in aggregate-induced quenching and lowers the quantum efficiency. 
Table 1. The Key EL characteristics of Devices A-D

\begin{tabular}{ccccc}
\hline & $\begin{array}{c}\text { Max } \\
\text { current } \\
\text { Deviciency } \\
(\mathrm{cd} / \mathrm{A})\end{array}$ & $\begin{array}{c}\text { Luminance } \\
(\mathrm{cd} / \mathrm{m} 2) \text { at } \\
11 \mathrm{~V}\end{array}$ & $\begin{array}{c}\text { CIE coordinates } \\
\text { at 6V }\end{array}$ & $\begin{array}{c}\text { CIE coordinates } \\
\text { at } 9 \mathrm{~V}\end{array}$ \\
A & $2.28 @ 13 \mathrm{~V}$ & 3126 & $(0.6143,0.356)$ & $(0.5598,0.3919)$ \\
B & $1.72 @ 15 \mathrm{~V}$ & 1892 & $(0.6151,0.3565)$ & $(0.5679,0.3875)$ \\
C & $0.29 @ 6 \mathrm{~V}$ & 307.3 & $(0.4361,0.4577)$ & $(0.4438,0.4694)$ \\
D & $0.63 @ 4 \mathrm{~V}$ & 194.2 & $(0.3593,0.3267)$ & $(0.5033,0.416)$ \\
\hline \hline
\end{tabular}

\section{Conclusions}

In conclusion, organic light-emitting device have been fabricated by using non-doped process. The fabrication of multilayer OLEDs did not involve the hard-to-control doping process using red fluorescent dye DCJTB, together with well known green fluorescent dye QAD as emitting layer,. To change the different hole injection layer, organic light-emitting device have been realized by using m-MTDATA, NPB, CBP, and NPB:CBP as holes injection layer, respectively. Its maximum luminance and maximum current efficiency of the device was $3126 \mathrm{~cd} / \mathrm{m}^{2}$ at $11 \mathrm{~V}$, and $2.28 \mathrm{~cd} / \mathrm{A}$ at $13 \mathrm{~V}$, respectively. In this work, we have studied the hole injection efficiencies at the interface of OLEDs. The luminance -voltage and 1 current efficiency -voltage characteristics indicated that the holes injection performance for m-MTDATA played role for the improved performance

\section{Acknowledgments}

This work was supported by the major project of science and technology office of Fujian Province of China (No.2014H0042), the Natural Science Foundation of Fujian Province of China (No. 2015J01664), the project of Science and Technology Research of Quanzhou, Fujian Provice of China (No.2013Z125, 2014Z137), and The 2016 annual national or ministries of the Quanzhou Normal University Prepare Research Foundation Project(No.2016YYKJ21)

\section{References}

[1]Lee S, Lee J H, Lee J H, Kim J J : Adv Funct Mater, Vol. 22(2012), p855

[2]Hung L S, Tang C W, Mason M G: Appl Phys Lett, Vol. 70(1997), p152

[3]Kang S, Park D, Kim S, Whang C, Jeong K, Im S : Appl Phys Lett, Vol. 81(2002), p2581

[4]M. A.Baldo, D. F. O'Brien, Y. You, A. Shoustikov, S. Sibley, M. E. Thompson, S. R. Forrest: Nature, Vol. 395(1998), p151

[5]Huang J, Xu Z, Yang Y. : Adv Funct Mater, Vol. 17(2007), p1966

[6]Zou Y, Deng Z B, Lv Z Y, Chen Z, Xu D H, Chen Y L: J Lumin, Vol. 130(2010), p959

[7]C.W.Seo,J.Y.Lee: Org.Electron. Vol. 12(2011), p1459

[8]G.J.Zhou,Q.Wang,X.Z.Wang,C.L.Ho,W.Y.Wong,D.G.Ma,L.X.Wang,Z.Y.Lin:J.Mater.Chem. 
Vol.20(2010),p7472

[9]J.H.Jou,S.M.Shen,C.R.Lin,Y.S.Wang,Y.C.Chou,S.Z.Chen,Y.C.Jou:

Org.Electron. Vol.12(2011),p865

[10] Mori T, Miyachi K, Mizutani T: J Phys D Appl Phys, Vol. 28(1995),p1461

[11] Kalinowski J, Di Marco P, Cocchi M, Fattori V, Camaioni N, Duff J: Appl Phys Lett, Vol. 68(1996),p 2317

[12] Kalinowski J, Di Marco P, Fattori V, Giulietti L, Cocchi M: J Appl Phys, Vol. 83(1998),p4242

[13]Y.L.Chang,B.A.Kamino,Z.B.Wang,M.G.Helander,Y.L.Rao,L.Chai,S.Wang,T.P.Bender, Z.H.Lu:Adv.Funct.Mater. Vol. 25(2013),p3204

[14]Y.Li,W.Zhang,L.T.Zhang,X.M.Wen,Y.M.Yin,S.H.Liu,W.F.Xie,H.Y.Zhao,S.L.Tao,Org.Electron. Vol. 14(2013),p3201

[15] Lee S-S, Ko D, Chung C-H, Cho S M:Synth Met, Vol. 128(2002),p51

[16] Yook K S, Lee J Y:J Ind Eng Chem. Vol. 16(2010),p181

[17] Hsiao C-H, Chen Y-H, LinT-C, Hsiao C-C, Lee J-H

[18] Tyagi P, Srivastava R, Kumar A, Tuli S, Kamalasanan M: J Lumin, Vol. 136(2013),p249 